\title{
National Survey of Drug Information Centers Practice in Saudi Arabia: Drug Monitoring and Patient Counseling at Ministry of Health Hospitals
}

Yousef Ahmed Alomi ${ }^{1^{*}}$, Saeed Jamaan Alghamdi ${ }^{2}$ and Radi Abdullah Alattyh ${ }^{2}$

${ }^{1} \mathrm{Head}$, National Clinical Pharmacy and Pharmacy Practice, Head, Pharmacy R \& D Administration, Ministry of Health, Riyadh, Saudi Arabia

${ }^{2}$ General Administration of Pharmaceutical Care, Ministry of Health, Riyadh, Saudi Arabia

\begin{abstract}
Objective: To explore the National Survey of Drug Information Centers practice in Saudi Arabia: Drug Monitoring and Patient Counseling at Ministry of Health Hospitals.

Methods: It is a cross-sectional four months national survey of Drug Information Services at Ministry of Health It contained ten domains with 181 questions designed by the authors. It derived from Internal Pharmaceutical Federation (FIP), American Society of Health-System Pharmacists best practice guidelines. This survey distributed to forty hospital pharmacies that run drug information services. In this study, the domain Drug Monitoring and Patient Counseling System explored and analyzed. It consisted of eight questions about the written policy and procedure and application methods for Drug Monitoring and Patient Counseling system in the drug information centers. All analysis is done through survey monkey system.
\end{abstract}

Results: The survey distributed to forty-five of hospitals, the response rate, was 40 ( $88.88 \%$ ) hospitals. Of those; the highest percentages of implementation of adverse reaction monitoring was ADR reporting forms are available did not exist in $3(7.5 \%)$ hospitals while $29(72.5 \%)$ of hospitals $100 \%$ applied the elements. The highest scores of implementation of the medications errors program were Definition of a significant medication error, the time frame for reporting and reporting format did not exist in $3(7.5 \%)$ hospitals while $27(67.5 \%)$ of hospitals $100 \%$ applied the elements. The highest percentages of implementation of patient counseling were the Proper storage of the medication did not exist in $6(15 \%)$ hospitals while only $20(50 \%)$ of hospitals $100 \%$ applied the elements.

Conclusion: There was a real application of drug monitoring and patient medication counseling system in drug information centers practice. Continues keep up with these levels is required with regular investigation of network drug information centers at Ministry of Health hospitals is preferable.

Keywords: Communication; Relationships; Factors; Job satisfaction; Pharmacy; Saudi Arabia

Abbreviations: KSA: Kingdom of Saudi Arabia; MOH: Ministry of Health; DIC: Drug Information Centers; IDS: Investigational Drug Services; PPS: Professional Publications Services

\section{Introduction}

The American society of health system pharmacist (ASHP) defined the Pharmaceutical Care before several years ago [1]. The Pharmaceutical Care consisted of several aspects and element. The drug monitoring and patient education were part of the principle of Pharmaceutical Care [1,2]. Over several years, back the American society of health system pharmacist conducted several studies to measure the level of the services in the United States of America. The authors found drug monitoring between and patient counseling. The study carried out by Alsultan and his colleagues in King of Saudi Arabia and it reported that the drug monitoring was between $8.6 \%$ $60.9 \%$ of hospitals, adverse drug reaction reporting system was $74.1 \%$ of the hospitals and patient counseling was $44 \%$ [3]. Recently by Alomi and his colleagues, they found drug monitoring adverse drug reaction prevention and reporting was $90.32 \%$ while medication errors prevention and documentation was $72.4 \%$ and patient education was $80.33 \%$ of hospital pharmacies respectively [4]. The adverse drug reaction or medication error reporting system or patient education in-depth detail system not mentioned. The role of drug information centers in this topic well defined by ASHP and included the medication monitoring with medication safety or patient counseling are elements as part of their duties [5]. Several studies of drug information centers network survey found that is drug monitoring was medication safety was $32.5 \%$ and adverse drug reaction reporting more than $50 \%$, while the one local study found reporting adverse drug reaction was $61.5 \%$ and patient education participating was $92.3 \%$ of the drug information centers [6-8]. The authors are not familiar with any international or local studies investigated in-depth detail about the drug monitoring and patient counseling provided by drug information centers. The goal of the survey to explore the national survey of a network of drug information centers in Saudi Arabia with emphasis on drug monitoring and patient counseling.

\section{Methods}

It is a national survey of Drug Information Services at $\mathrm{MOH}$. It contained ten domains; Leadership and Practice Management, Medication Addition and Deletion System, Hospital Formulary System, Medication Safety System, Professional and Public Education. The Evidence-Based Medicine-Therapeutics Guidelines

*Corresponding author: Yousef Ahmed Alomi, Head, National Clinical Pharmacy and Pharmacy Practice, Head, Pharmacy R \& D Administration, Ministry of Health P.O. BOX 100, Riyadh 11392, Riyadh, Saudi Arabia, Tel: +966504417712; E-mail: yalomi@gmail.com

Received: October 23, 2017; Accepted November 02, 2017; Published November 09, 2017

Citation: Alomi YA, Alghamdi SJ, Alattyh RA (2017) National Survey of Drug Information Centers Practice in Saudi Arabia: Drug Monitoring and Patient Counseling at Ministry of Health Hospitals. J Pharmacovigil 5: 246. doi:10.4172/2329-6887.1000246

Copyright: ( 2017 Alomi YA, et al. This is an open-access article distributed under the terms of the Creative Commons Attribution License, which permits unrestricted use, distribution, and reproduction in any medium, provided the original author and source are credited. 
(EBM-TG), Medication-Use Evaluation, Pharmacoeconomics System, Investigational Drug Services (IDS) and Professional Publications Services (PPPS) and Ethical and Legal Issue. It consisted of 181 questions designed by the authors. It drove from Internal Pharmaceutical Federation (FIP), American Society of HealthSystem Pharmacists best practice guidelines, the international standard of Joint Commission of Hospital Accreditation. In addition to the local standards of Saudi center of health care accreditation and minimum standards of drug information centers in Saudi Arabia $[9,5,10,11]$. This survey distributed to forty hospital pharmacies that run drug information services. The information of hospitals services from extensive records of General Administration of pharmaceutical care. In this study, the domain of Drug Monitoring and Patient Counseling at $\mathrm{MOH}$ explored and analyzed. It consisted of 16 questions about the written policy and procedure for drug followup to and 17 issues of Patient Counseling at $\mathrm{MOH}$. It included the written policy and procedure for ADR, Definition of significant or severe ADR and time frame for reporting, ADR reporting forms are available, the Intensive analysis performed for all significant or severe ADRs, Notification of treating physician. There is evidence that the patient receives appropriate care for ADR, There is evidence that the medical record has flagged for known allergies, Process for improving ADR reporting, Evidence of reporting any severe or unexpected ADR to NDIC the MOH. Written policy and procedure for medication error reporting, Definition of a significant medication error, the time frames for reporting and reporting format. Evidence of active reporting exists. Intensive root-cause analysis performed for all significant medication errors, evidence for using reported data to improve medication use process and reduce the error rate. Mechanism to prevent serious medication errors (e.g., removal of concentrated intravenous potassium, magnesium, hypertonic saline, other high-risk stocks from nursing units). Patient and families offered education for dispensed medication. Written drug counseling materials are available in easily understandable language (Arabic and English), the drug's trade name, generic name, common synonym or other descriptive names and, when appropriate, its therapeutic class and efficacy. The drugs' use and expected benefits and action. That may include whether the medication intended to cure a disease, eliminate or reduce symptoms, arrest or slow the disease process or prevent the disease or a symptom. The medications expected the onset of action and what to do if the action does not occur. The drug's route, dosage form, dosage and administration schedule (including duration of therapy). Directions for preparing and using or administering the medication. That may include the adaptation to fit patient's lifestyles or work environments. Action to take in case of a missed dose. Precautions are observed during the medication's potential risks about benefits. Potential common and severe adverse effects that may occur, actions to prevent or minimize their occurrence and steps to take if they occur, including notifying the prescriber, pharmacist or another healthcare provider. The techniques for self-monitoring of pharmacotherapy, potential drug-drug interactions (including nonprescription), drug-food and drug-disease interactions or contraindications should be done. The medication's relationships to radiological and laboratory procedures (e.g., the timing of doses and potential interference with the interpretation of results) has to be examined. Prescription refill authorizations or the process for obtaining refills. Instructions are for 24-hour access to a pharmacist. Moreover, the proper storage of the medication. Proper disposal of contaminated or discontinued medications and used administration devices. All analysis is done through survey monkey system.

\section{Results}

The survey distributed to 45 of hospitals, the response rate, was 40 $(88.88 \%)$ hospitals. Of that $35 \%$ large hospitals, $37.5 \%$ medium size hospitals, $17.5 \%$ small size hospitals and $10 \%$ National and Regional Drug Information Centers. OF those, fifteen hospitals only accredited by CIBAHI and eight hospitals only accredited by Joint commission while none of all them accredited by ASHP or Canada. The majority of responders were Saudi 38 (95\%) and 28 (70\%) were male gender and $12(30 \%)$ were female as explored in Table 1 . The highest percentages of implementation of adverse reaction monitoring were ADR reporting forms are available did not exist in 3 (7.5\%) hospitals while only 29 (72.5\%) of hospitals $100 \%$ applied the elements. Followed by written policy and procedure for ADR not existed in 3 (7.5\%) hospitals while only $25(62.5 \%)$ of hospitals $100 \%$ applied the elements. The definition of significant or severe ADR and time frame for reporting did not exist in 3 (7.5\%) hospitals while only 23 (57.5\%) of hospitals $100 \%$ applied the elements. The highest scores of implementation of the medications errors program were definition of a significant medication error, the time frame for reporting and reporting format did not exist in $3(7.5 \%)$ hospitals while 27 (67.5\%) of hospitals $100 \%$ applied the elements. Followed by written policy and procedure for medication error reporting did not exist in 3 (7.5\%) hospitals while only 27 (67.5\%) of hospitals $100 \%$ applied the elements. Moreover, evidence of actual reporting did not exist in $3(7.5 \%)$ hospitals while only $21(52.5 \%)$ of hospitals $100 \%$ applied the elements. The highest percentages of implementation of patient counseling were Proper storage of the medication did not exist in $6(15 \%)$ hospitals while only $20(50 \%)$ of hospitals $100 \%$ applied the elements. Followed by The drugs route, dosage form, dosage and administration schedule (including duration of therapy) did not exist in 7 (17.5\%) hospitals while only 15 (37.5\%) of hospitals $100 \%$ applied (Tables $2-4$ ) the elements. Proper disposal of contaminated or discontinued medications and used administration devices did not exist in $7(17.5 \%)$ hospitals while only $18(45 \%)$ of hospitals $100 \%$ applied the elements. In addition to instructions are for 24-hour access to a pharmacist did not exist in 9 (22.5\%) hospitals while only 16 (40\%) of hospitals $100 \%$ applied the elements.

\section{Discussion}

The one objective of the Ministry of Healthcare strategic plan was patient safety [12]. It included medication safety, administration safety and prescribing safety. The $\mathrm{MOH}$ established a sentinel event reporting system to follow up all type of sentinel events [12]. According to that, the general administration of Pharmaceutical Care established medication safety program [13]. The program consisted of prevention, monitoring medication events, reporting of medication errors including the type of the sentinel events, adverse drug reaction reporting system and drug quality reporting system [14]. In addition to basic medication safety course to all healthcare professionals and annual ISMP self-assessment survey of medication safety at hospitals and primary care centers. The pharmacy administration established patient counseling program with an emphasis on chronic disease [15]. The patient medication education is done at ambulatory care pharmacy or during discharge from hospitals or through patient medication education clinic operated by a pharmacist. The program focused on common chronic and cornered large population in the king of Saudi Arabia. It included Diabetes mellitus, Asthma and Epilepsy. The authors did this survey to explore the drug therapy monitoring $g$ and patient education as part of drug information centers activities. The findings showed that adverse drug reaction system almost as reported by Alsultan, et al. both studies were done by Rosenberg, JM, et al. conducted in 2004 and 2009 and an investigation done by Alamri 
Citation: Alomi YA, Alghamdi SJ, Alattyh RA (2017) National Survey of Drug Information Centers Practice in Saudi Arabia: Drug Monitoring and Patient Counseling at Ministry of Health Hospitals. J Pharmacovigil 5: 246. doi:10.4172/2329-6887.1000246

Page 3 of 5

\begin{tabular}{|c|c|c|c|c|c|c|c|c|c|c|}
\hline \multicolumn{3}{|c|}{ Size, ownership and accreditation of respondents } & \multicolumn{2}{|c|}{ Nationality } & \multicolumn{2}{|c|}{ Sex } & \multicolumn{4}{|c|}{ Accreditation } \\
\hline $\begin{array}{l}\text { Hospital size (Number } \\
\text { of staffed beds) }\end{array}$ & $\begin{array}{l}\text { Number of } \\
\text { hospitals }\end{array}$ & Percentages & Saudi & Non-Saudi & Male & Female & CIBAHI & $\mathrm{JCI}$ & Canada & ASHP \\
\hline \multicolumn{11}{|c|}{ Small } \\
\hline$<50$ & 1 & $2.50 \%$ & $1(2.5 \%)$ & $0(0 \%)$ & $1(2.5 \%)$ & $0(0 \%)$ & $0(0 \%)$ & $0(0 \%)$ & $0(0 \%)$ & $0(0 \%)$ \\
\hline $50-99$ & 6 & $15 \%$ & $6(15 \%)$ & $0(0 \%)$ & $6(15 \%)$ & $0(0 \%)$ & $0(0 \%)$ & $0(0 \%)$ & $0(0 \%)$ & $0(0 \%)$ \\
\hline \multicolumn{11}{|c|}{ Medium } \\
\hline 100-199 & 7 & $17.50 \%$ & $7(17.5 \%)$ & $0(0 \%)$ & $6(15 \%)$ & $1(2.5 \%)$ & $0(0 \%)$ & $0(0 \%)$ & $0(0 \%)$ & $0(0 \%)$ \\
\hline 200-299 & 8 & $20 \%$ & $7(17.5 \%)$ & $1(2.5 \%)$ & $5(12.5 \%)$ & $3(7.5 \%)$ & $5(25 \%)$ & $2(10 \%)$ & $0(0 \%)$ & $0(0 \%)$ \\
\hline \multicolumn{11}{|c|}{ Large } \\
\hline 300-399 & 7 & $17.50 \%$ & $7(17.5 \%)$ & $0(0 \%)$ & $4(10 \%)$ & $3(7.5 \%)$ & $4(20 \%)$ & $2(10 \%)$ & $0(0 \%)$ & $0(0 \%)$ \\
\hline 400-599 & 7 & $17.50 \%$ & $6(15 \%)$ & $1(2.5 \%)$ & $5(12.5 \%)$ & $2(5 \%)$ & $6(30 \%)$ & $4(20 \%)$ & $0(0 \%)$ & $0(0 \%)$ \\
\hline More than or equal 600 & 0 & $0 \%$ & $0(0 \%)$ & $0(0 \%)$ & $0(0 \%)$ & $0(0 \%)$ & $0(0 \%)$ & $0(0 \%)$ & $0(0 \%)$ & $0(0 \%)$ \\
\hline \multicolumn{11}{|c|}{ Very large } \\
\hline Medical cities & 0 & $0 \%$ & $0(0 \%)$ & $0(0 \%)$ & $0(0 \%)$ & $0(0 \%)$ & $0(0 \%)$ & $0(0 \%)$ & $0(0 \%)$ & $0(0 \%)$ \\
\hline $\begin{array}{c}\text { National and Regional } \\
\text { Drug Information } \\
\text { Centers }\end{array}$ & 4 & $10 \%$ & $4(10 \%)$ & $0(0 \%)$ & $1(2.5 \%)$ & $3(7.5 \%)$ & $0(0 \%)$ & $0(0 \%)$ & $0(0 \%)$ & $0(0 \%)$ \\
\hline Missing no-response & 0 & $0 \%$ & $0(0 \%)$ & $0(0 \%)$ & $0(0 \%)$ & $0(0 \%)$ & $20(50 \%)$ & $20(50 \%)$ & $20(50 \%)$ & $20(50 \%)$ \\
\hline Total respondents & 40 & $100 \%$ & $38(95 \%)$ & $2(5 \%)$ & $28(70 \%)$ & $12(30 \%)$ & $20(50 \%)$ & $20(50 \%)$ & $20(50 \%)$ & $20(50 \%)$ \\
\hline \multicolumn{11}{|l|}{ Ownership } \\
\hline MOH-Hospitals & 40 & $100 \%$ & & & & & & & & \\
\hline Non-MOH Hospitals & 0 & $0 \%$ & & & & & & & & \\
\hline Privates & 0 & $0 \%$ & & & & & & & & \\
\hline
\end{tabular}

Table 1: Size, ownership and accreditation of respondents.

\begin{tabular}{|c|c|c|c|c|c|c|c|}
\hline Answer options & $\mathbf{1}$ & $\mathbf{2}$ & $\mathbf{3}$ & $\mathbf{4}$ & $\mathbf{5}$ & Rating average & Response count \\
\hline Written policy and procedure for ADR. & 3 & 1 & 1 & 10 & 25 & 4.33 & 40 \\
\hline Definition of significant or serious ADR and timeframe for reporting. & 3 & 0 & 3 & 10 & 23 & 4.28 \\
\hline ADR reporting forms are available. & 3 & 0 & 3 & 5 & 29 & 4.43 \\
\hline Intensive analysis is performed for all significant or serious ADRs. & 5 & 4 & 5 & 9 & 17 & 3.73 & 40 \\
\hline Notification of treating physician. & 3 & 1 & 5 & 8 & 23 & 4.18 & 40 \\
\hline There is evidence that the patient receives appropriate care for ADR. & 5 & 4 & 5 & 8 & 18 & 3.75 & 40 \\
\hline There is evidence that the medical record has flagged for known allergies. & 7 & 4 & 6 & 9 & 14 & 3.48 & 40 \\
\hline Process for improving ADR reporting. & 5 & 2 & 9 & 9 & 15 & 3.68 & 40 \\
\hline Evidence of reporting any severe or unexpected ADR to NDIC the MOH. & 5 & 4 & 8 & 9 & 14 & 3.58 & 40 \\
\hline Answered question & & & 40 \\
\hline Skipped question & & & \\
\hline
\end{tabular}

1: DIC is NOT applying the elements; 2 : DIC is applying $25 \%$ of the elements; 3 : DIC is applying $50 \%$ of the elements; 4 : DIC is applying $75 \%$ of the elements; 5 : DIC is applying $100 \%$ of the elements

Table 2: Drug Information Centers had a process for monitoring, detecting and reporting adverse drug reactions (ADRs).

$[3,6-8]$. While it lowered than Alomi et al. study, There is improving the adverse drug reactions prevention and reporting system but in such indepth detail not mentioned in the Alomi, et al. [4]. The patient education results are better than a study done by Alsultan, et al. Rosenberg et al. conducted in $2004[6,7]$. While it lower by a recent study was done by Alomi, et al. and investigation done by Alamri [8]. The system is improving as compared with old studies while the results were lower than recent research due to the system not mention in-depth details looks like our study and drug information pharmacist not involved all time with patient education, the most areas practiced the system were an outpatient pharmacy and inpatient pharmacy during patient discharge. The findings of medication error prevention and documentation better than Alomi, et al. [4] due to depth detail not mentioned in the study and most of the medication error system done medication safety officers at the hospital pharmacies. Other results could not compare them because they not investigated. The network of drug information centers need to keep up with this level of drug monitoring include adverse drug and medication while it needs more involvement in public drug counseling and more educational publications about medication for distribution at ambulatory care pharmacies and pharmacy discharged areas. 
Citation: Alomi YA, Alghamdi SJ, Alattyh RA (2017) National Survey of Drug Information Centers Practice in Saudi Arabia: Drug Monitoring and Patient Counseling at Ministry of Health Hospitals. J Pharmacovigil 5: 246. doi:10.4172/2329-6887.1000246

Page 4 of 5

\begin{tabular}{|c|c|c|c|c|c|c|c|}
\hline Answer options & 1 & 2 & 3 & 4 & 5 & Rating average & Response count \\
\hline Written policy and procedure for reporting medication error & 3 & 0 & 5 & 5 & 27 & 4.33 & 40 \\
\hline $\begin{array}{l}\text { Definition of a significant medication error, the timeframe for reporting and } \\
\text { reporting format. }\end{array}$ & 3 & 0 & 3 & 7 & 27 & 4.38 & 40 \\
\hline Evidence of active reporting exists. & 3 & 2 & 7 & 7 & 21 & 4.03 & 40 \\
\hline $\begin{array}{l}\text { Intensive root-cause analysis is performed for all significant medication } \\
\text { errors. }\end{array}$ & 5 & 3 & 5 & 10 & 17 & 3.78 & 40 \\
\hline $\begin{array}{l}\text { Evidence for using reported data to improve drug use process and reduce } \\
\text { the error rate. }\end{array}$ & 5 & 1 & 7 & 9 & 18 & 3.85 & 40 \\
\hline $\begin{array}{l}\text { Mechanism to prevent serious medication errors (e.g., removal of } \\
\text { concentrated intravenous potassium, magnesium, hypertonic saline, other } \\
\text { high-risk stocks from nursing units). }\end{array}$ & 4 & 1 & 5 & 9 & 21 & 4.05 & 40 \\
\hline \multicolumn{7}{|l|}{ Answered question } & 40 \\
\hline \multicolumn{7}{|c|}{ Skipped question } & 0 \\
\hline \multicolumn{7}{|c|}{ 1: DIC is NOT applying the elements; 2 : DIC is applying $25 \%$ of the elements; $3: \mathrm{DIC}$ is applying $50 \%$ of the elements; } & \\
\hline \multicolumn{7}{|l|}{ 4: DIC is applying $75 \%$ of the elements; $5:$ DIC is applying $100 \%$ of the elements } & \\
\hline
\end{tabular}

Table 3: Drug Information Centers had a process for monitoring, identifying and reporting significant medication errors (ME).

\begin{tabular}{|c|c|c|c|c|c|c|c|}
\hline Answer options & 1 & 2 & 3 & 4 & 5 & Rating average & Response count \\
\hline Patient and families offered education for dispensed medication. & 6 & 2 & 14 & 5 & 13 & 3.43 & 40 \\
\hline $\begin{array}{l}\text { Written drug counseling materials are available in easily understandable language } \\
\text { (Arabic and English), lexicomp* }\end{array}$ & 6 & 2 & 14 & 6 & 12 & 3.4 & 40 \\
\hline $\begin{array}{l}\text { The medication's trade name, generic name, common synonym, or other descriptive } \\
\text { names and, when appropriate, its therapeutic class and efficacy. }\end{array}$ & 6 & 2 & 10 & 11 & 11 & 3.48 & 40 \\
\hline $\begin{array}{l}\text { The medication's use and expected benefits and action. This may include whether the } \\
\text { medication is intended to cure a disease, eliminate or reduce symptoms, arrest or slow } \\
\text { the disease process, or prevent the disease or a symptom. }\end{array}$ & 7 & 2 & 12 & 6 & 11 & 3.32 & 38 \\
\hline $\begin{array}{l}\text { The medications expected the onset of action and what to do if the action does not } \\
\text { occur. }\end{array}$ & 8 & 3 & 8 & 7 & 13 & 3.36 & 39 \\
\hline $\begin{array}{c}\text { The medication's route, dosage form, dosage and administration schedule (including } \\
\text { duration of therapy). }\end{array}$ & 7 & 0 & 10 & 8 & 15 & 3.6 & 40 \\
\hline $\begin{array}{c}\text { Directions for preparing and using or administering the medication. This may include the } \\
\text { adaptation to fit patient's lifestyles or work environments. }\end{array}$ & 8 & 3 & 7 & 8 & 14 & 3.43 & 40 \\
\hline Action to be taken in case of a missed dose. & 6 & 3 & 11 & 8 & 12 & 3.43 & 40 \\
\hline Precautions to observe the medication's potential risks about benefits. & 7 & 5 & 8 & 8 & 12 & 3.33 & 40 \\
\hline $\begin{array}{l}\text { Potential frequent and severe adverse effects that may occur, actions to prevent } \\
\text { or minimize their occurrence and steps to take if they occur, including notifying the } \\
\text { prescriber, pharmacist, or another healthcare provider. }\end{array}$ & 8 & 2 & 9 & 10 & 11 & 3.35 & 40 \\
\hline Techniques for self-monitoring of pharmacotherapy. & 10 & 5 & 9 & 5 & 11 & 3.05 & 40 \\
\hline $\begin{array}{l}\text { Potential drug-drug (including nonprescription), drug-food and drug-disease interactions } \\
\text { or contraindications. }\end{array}$ & 5 & 6 & 10 & 8 & 11 & 3.35 & 40 \\
\hline $\begin{array}{l}\text { The medication's relationships to radiological and laboratory procedures (e.g., the timing } \\
\text { of doses and potential interference with the interpretation of results). }\end{array}$ & 10 & 5 & 9 & 5 & 11 & 3.05 & 40 \\
\hline Prescription refill authorizations and the process for obtaining refills. & 8 & 5 & 8 & 6 & 12 & 3.23 & 39 \\
\hline Instructions are for 24-hour access to a pharmacist. & 9 & 2 & 8 & 5 & 16 & 3.43 & 40 \\
\hline Proper storage of the medication. & 6 & 3 & 5 & 6 & 20 & 3.78 & 40 \\
\hline $\begin{array}{c}\text { Proper disposal of contaminated or discontinued medications and used administration } \\
\text { devices. }\end{array}$ & 7 & 5 & 4 & 6 & 18 & 3.58 & 40 \\
\hline \multicolumn{7}{|l|}{$\begin{array}{ll}\text { Answered question } \\
\end{array}$} & 40 \\
\hline \multicolumn{7}{|l|}{ Skipped question } & 0 \\
\hline \multicolumn{7}{|c|}{ 1: DIC is NOT applying the elements; 2 : DIC is applying $25 \%$ of the elements; 3 : DIC is applying $50 \%$ of the elements; } & \\
\hline \multicolumn{7}{|l|}{ 4: DIC is applying $75 \%$ of the elements; 5 : DIC is applying $100 \%$ of the elements } & \\
\hline
\end{tabular}

Table 4: Drug Information Centers had a system developed for patient and family education and counseling before going home.

\section{Conclusion}

There was a proper implementation of medication safety including adverse drug reactions and medication error prevention and reporting system. In addition to patient medication education. The network needed more emphasis on publication education through lecturing and published a patient pamphlet for distribution at ambulatory care pharmacy during patient discharge. More, regular survey of drug information centers every two to three is required to follow up the improvement thoroughly at Ministry of Health hospital pharmacies in Kingdom of Saudi Arabia.

\section{References}

1. American Society of Hospital Pharmacists (1993) ASHP statement on pharmaceutical care. Am J Hosp Pharm 50: 1720-1723.

2. American Society of Hospital Pharmacists (1996) ASHP guidelines on a standardized method for pharmaceutical care. Am J Health Syst Pharm. 53 1713-1716.

3. Alsultan MS, Mayet AY, Khurshid F, Al-Jedai AH (2013) Hospital pharmacy practice in Saudi Arabia: Drug monitoring and patient education in the Riyadh region. Saudi Pharm J 21: 361-370. 
Citation: Alomi YA, Alghamdi SJ, Alattyh RA (2017) National Survey of Drug Information Centers Practice in Saudi Arabia: Drug Monitoring and Patient Counseling at Ministry of Health Hospitals. J Pharmacovigil 5: 246. doi:10.4172/2329-6887.1000246

Page 5 of 5

4. Alomi YA, Alghamdi SJ, Alattyh RA, Alshahrani AM, Shorog EM, et al. (2017) National survey of pharmacy parctice at $\mathrm{MOH}$ hospitals in Saudi Arabia 2016: Technology and clinical pharmacy sevies. Value in Health 20: A39.

5. Ghaibi S, Ipema HGM (2015) ASHP guideline on the pharmacist's role in providing drug information. Am J Health Syst Pharm 72: 573-577.

6. Rosenberg JM, Koumis T, Nathan JP, Cicero LA, McGuire H (2004) Current status of pharmacist-operated drug information centers in the United States. Am J Health Syst Pharm 61: 2023-2032.

7. Rosenberg JM, Schilit S, Nathan JP, Zerilli T, Mcguire H (2009) Update on the status of 89 drug information centers in the United States. Am J Health Syst Pharm 66: 1718-1722.

8. Alamri SA, Ali Al Jaizani R, Naqvi A, Ghamdi MSA (2017) Assessment of drug information service in public and private sector tertiary care hospitals in the eastern province of Saudi Arabia. Pharmacy (Basel) 5: 37.
9. Vernon G, Dvorkin L, Vidotti CCF, Woods D (2005) Requirements for Drug Information Centres. FIP Pharmacy Information Section.

10. Medication Management (MM) (2015) In: National Hospital Standards [Internet] 2nd edn. Saudi Central Board for Accreditation of Healthcare Institutions. 194-211.

11. The Joint Commission. Comprehensive Accreditation Manuals. Joint Commission Resources.

12. Ministery of Health (2011) A Cheivements 2013. 1st edn. Riyadh, Saudi Arabia Ministry of Health, Saudi Arabia, pp: 132-135.

13. Alomi YA (2015) National medication safety program at ministry of health in Saudi Arabia. J Pharmacovigil 3: 1-2.

14. Alomi YA, Kamal E, Alomi, Kamal (2016) National drug quality reporting system at ministry of health in Saudi Arabia. J Pharmacovigil 4: 208.

15. Alomi $Y$ (2015) National pharmacy administration programs at ministry of health in Saudi Arabia. BAOJ Pharm Sci 1:1-2 